\title{
SMART LIGHTING SYSTEM FOR VEHICLES TO AVOID BLIND SPOTS
}

\section{SANTHOSH KUMAR ${ }^{1} \&$ SHUJAYAT KHAN ${ }^{2}$}

${ }^{l}$ PG Scholar Student, Department of Mechanical Engineering, Koneru Lakshmaiah Educational Foundation, Guntur, Andhra Pradesh, India

${ }^{2}$ Project Manager, Department of Mechanical Engineering, Koneru Lakshmaiah Educational Foundation, Guntur, Andhra Pradesh, India

\begin{abstract}
Despite having 70-75\% lesser traffic during the night, 50-55\% of total accidents are recorded to be occurred during this time. Occurrence of blind spot or glare effects is also a reason for these accidents. Hence our work is aimed at avoiding all such effects, improving the safety during night journey. Here, we developed a very cost effective method, which will improve the vision, illuminating the path effectively, thus eliminating the chance of accident. This system is developed using Arduino UNO micro-controller. Two servo990 motors are engaged with this micro-controller, which are mounted with LEDs, replicating the head lights of the vehicles. These servo motors are rotated by means of a multiple turn potentiometer and the light intensity is thus negotiated along the curvature of the road. Beside the system is also equipped with LDR sensor for reducing the glare effect, by decreasing the intensity of head light.

KEYWORDS: Blind Spot, Glare Effect, Negotiation, Curvature, Light Intensity
\end{abstract}

Received: Apr 04, 2020; Accepted: Apr 24, 2020; Published: May 14, 2020; Paper Id.: IJMPERDJUN202048

\section{INTRODUCTION}

Night travels have become a nightmare these days due to increase in accidents. There are various reasons that account for accidents on roads[8]. These include bad weather conditions, steepy roads, lack of proper illumination of path, inability to watch the objects due to blind spots[1]. Illuminating the path, eliminating the blind spots and glare effects are controllable factors in reducing the damage. Thus, our work is especially stressed at avoiding such blind spot situations.

Blind spots occur due to two reasons notably. Light intensity coming from the opposite vehicle fall directly into the drivers eyes, causing his eyes blinded temporarily for a few seconds. These are also termed as glare effects of light. Medically, this effect is called troxler effect[11]. Temporary blindness to driver's eyes is highly dangerous, especially at night. This effect would be severe when the vehicle is moving along the cures of the road.

Blind spots will also occur when the vehicle is moving along the curvature of the road [11]. The objects that are at immediate adjacent to the vehicle (on the curve), will not be illuminated with the conventional lighting of the vehicle. This is because the light rays from the head lamps will travel tangentially to the curvature. Since the lights being static on vehicle, the adjacent side portion of the path will not get illuminated.

Taking theses constrains into consideration, an alternative solution has been developed utilising the technology available, which would not increase the total end cost of the vehicle. This system consists of Arduino UNO as controlling system. The light coming from the opposite vehicle falls on to the LDR sensor of the system. This light intensity is converted into voltage. Once this voltage is reached to the fixed threshold value, the led 
intensity will be decreased automatically. This reduction in intensity will eliminate the glare effect or troxler effect. Thus, the driver eyes will not be blinded, making things clear to his eyes.

The servo motors are rotated in the ratio of 12:1. This is because in general, the gear ratio of the vehicle will range from 12:1 to 20:1 [9]. This means when your steering wheel is rotated through 12 degrees, the wheel of the vehicle will rotate only through 1 degree. Since most of the modern vehicles are supposed to have power steering, 12:1 gear ratio is taken as the base. When the rotary potentiometer which is connected to UNO, is rotated through certain angle, the servo motor is made to rotate in analogy to it in the ratio mentioned. Thus potentiometer angle and servo motor angles will be in the ratio of 12:1, following the gear ratio of the vehicle. Hence LEDS placed on the servo shaft will rotate in analogy with the wheel angle. This is done because the angular movement of the vehicle will depend on the wheel angle. Now that, both wheel angle and the servo angles being same, the path through which the vehicle moves, will be illuminated well.

Thus, when the vehicle is moving along a curve on the road, the light rays travel along that curvature. Conventional lighting system will have light rays travelling tangential to the road curve, but with the current system light rays travel along the curvature of the road. Hence the objectives of the work, to reduce the glare effect and to turn the head lamps along the road curve can be achieved satisfactorily.

\section{LITERATURE REVIEW}

- S Shreyas have developed an accident prevention adaptive head light system using Atmel processor with stepper motors and dc generator. The dc generator is mounted on steering wheel. When the steering wheel is rotated, the dc generator will generate the emf based on the rotation angle. The generated EMF will be taken as input to the micro-controller and the corresponding angle through which the stepper to be rotated will be calibrated.

- Priyanka M Dubahave presented a paper on development of vehicle adaptive lighting system utilising ultra sonic sensor, LPC 2148 micro-controller, stepper motors and drivers. The ultra sonic sensor senses the approach of the opposite vehicle. Based on the distance calculated by the sensor, if the value reaches the threshold value, the head light is turned down in direction. For horizontal rotation of the light, image sensor was adopted. The image taken by the sensor is processed by converting it from RGB image to HSV plane. Based on the conversion, the angle to be rotated is calculated. The calculated output is sent to the controller to bring the rotation in stepper motor.

- G Ravi Kumar has developed a system using LPC 2138 micro-controller. In the proposed system, the light intensity is adjusted based on the speed of the vehicle. The system consists of two lights, high beam light and low beam light. Taking $50 \mathrm{kmph}$ as the threshold speed, the lights are operated. When the speed of the vehicle is below the threshold, lower beam light is switched on. Similarly, when the vehicle speed exceeds the threshold value, the lower beam light is switched off and the high beam light is switched on. The horizontal movement of the lights are controlled by dc motor depending on the respected direction; the steering wheel is rotated through.

- Kalyani Gaikad presented a paper on versatile frame work for smart lighting in vehicles using LIN and CAN network. In their work, they considered local communication is an effective way to transfer data of luminance of external light available and vehicle angle of tilt. Their system consists of three controlling devices along with two protocols. 
- Vaishali D Todkar has proposed a system for smart vehicle lighting utilising image sensor and dc motors. The dc motors are operated in analogy with the ultrasonic sensor and the image sensor is used for horizontal rotation of the vehicle. The system is simulated using Matlab. The images captured by the image sensor are fed to the Matlab software and the images are processed to determine the angle of rotation for the servo motors. The output (angle rotation) is calibrated and the servo motors are rotated for the said so.

- Ganesh Shinde has developed the design of rack-pinion mechanism for turning the head lamps of the vehicles. The rack and pinion mechanism is developed based on the gear ratio of the vehicle. It consists of mechanism of four bar chain link, which are mechanically operated. In the design developed, the long steering rack replaced the track rod. These are attached to tie rods at one end. When the steering wheel is rotated, the pinion gear tilts and the rack is moved as a reaction. Thus, the head lights mounted on its ends are tilted in analogy with the gear. The gear ratio of vehicles differs from one to another. This can be adjusted by changing the size of the pinion gear.

- Raju T has designed and fabricated a steering controlled light system for TATA Indica vehicle. This design is based on Ackerman steering gear mechanism. The maximum can rotated with this design is 36 degrees. The maximum angle to be rotated is observed from this work.

\section{HARDWARE FOR THE PROPOSED SYSTEM}

\section{1) Arduino}

UNO:Arduino UNO is a ATmega 328p microchip based micro-controller. It is capable of programming with Arduino Integrated Development Environment using a B type USB cable. The data is transferred and communicated through its 14 digital I/O pins and 6 analogue $\mathrm{I} / \mathrm{O}$ pins. The operating voltage is $5 \mathrm{~V}$, though the input voltage can be varied between 7 $20 \mathrm{~V}$. It has SRAM of $2 \mathrm{~kb}$, flash memory of $32 \mathrm{~kb}$, EEPROM of $1 \mathrm{~kb}$, and a clock speed of $16 \mathrm{MHz}$. The micro-controller is interfaced with LDR sensor, rotary potentiometer, two servo 996 motors.

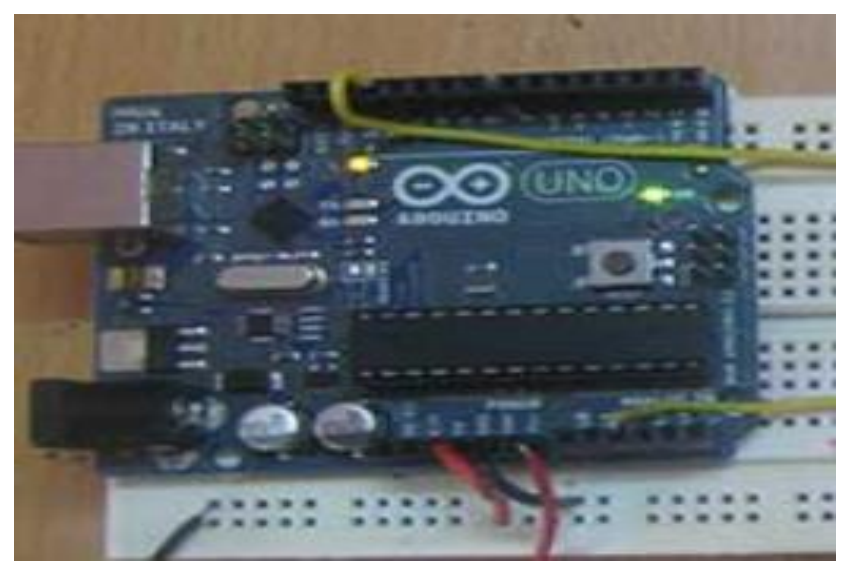

Figure 1: Arduino Uno.

\section{2) LDR Sensor}

Light Dependent Resistive sensor is a light sensitive sensor. It is manufactured from a semi-conductor material cadmium sulphide. It works on the principle of change in resistance. It has higher resistance values up to $1 \mathrm{Mohm}$ in dark environment and few ohms in light environments. The light incident on to the LDR sensor will get converted to electrical energy. Thus, LDR can be effectively utilised in calculating the light intensities. 


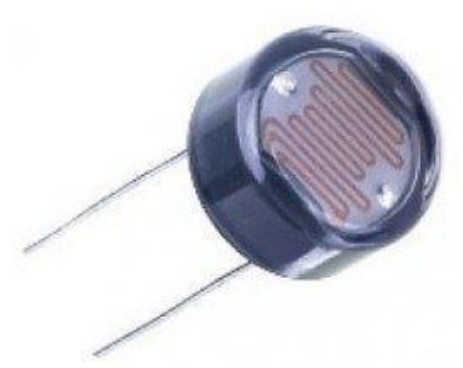

Figure 2: LDR Sensor.

\section{3) Multiple Rotary Potentiometer}

A potentiometer is a variable resistor, whose resistance can be varied or adjusted by mechanical movement of rotary contact. It consists of three terminals, of which two are connected to resistive element and the third terminal to rotary contact. Generally, a potentiometer can be rotated through $180^{\circ}$. Here, we adopted multiple turn $\left(3\right.$ turn- $\left.1080^{\circ}\right)$ potentiometer, because the steering is rotated beyond $180^{\circ}$ and up to $540^{\circ}$ [10].

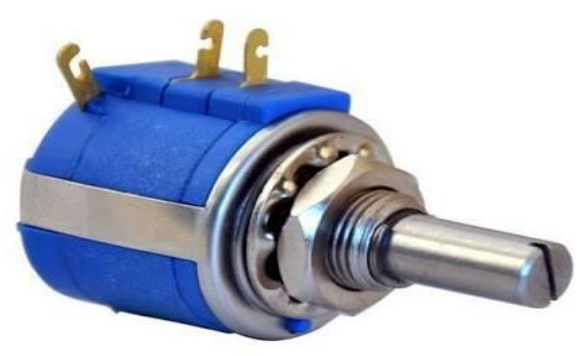

Figure 3: Multiple Turn Potentiometer.

\section{4) Servo sg90 Motor}

Servo motors are used in applications that require high precision in speed and position. These motors are energy efficient and powerful. A servo motor can be rotated from 0 to $180^{\circ}$. It works on pulse width modulation. Based on the width of the pulse, the motor is rotated either in clock-wise or anti clock-wise directions.

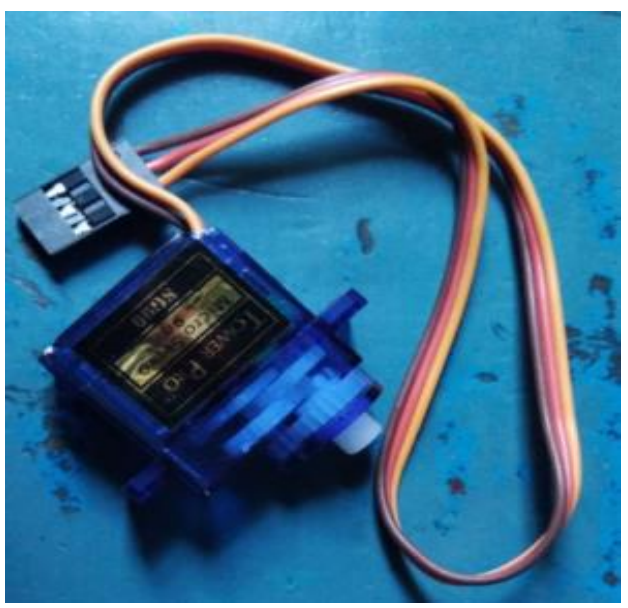

Figure 4: Servo sg90 Motor. 


\section{5) 1 Watt Leds}

1 watt led bulbs are mounted on the servo motor output shaft. These leds have approximately about 12.5 lumens of intensity.

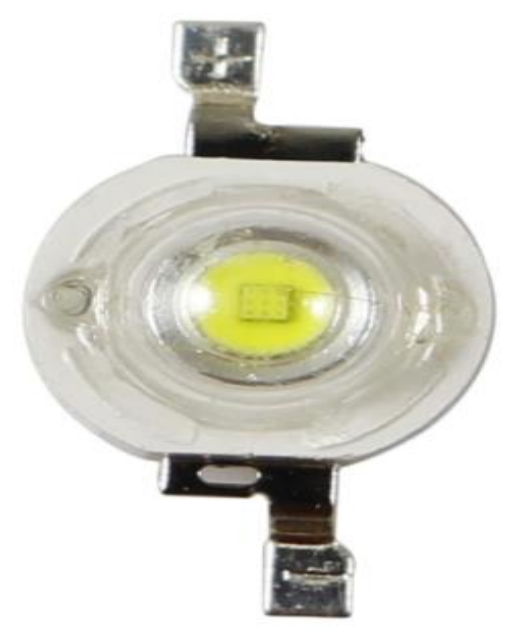

Figure 5: 1-Watt Led Bulb.

\section{ARCHITECTURE AND WORKING OF THE SYSTEM}

The proposed smart lighting system consists of Arduino UNO micro-controller, LDR sensor, multiple rotary potentiometer, two servo motors and two 1-watt led bulbs. The interfaced LDR sensor and potentiometers are used for reducing the intensity of the head lamps and to rotate the servo motors respectively.

When light is incident on to the LDR sensor, the light intensity is converted into the electrical energy. As the incident light intensity increases the conductivity of the sensor increases drastically and output voltage is generated in the analogous form. This analog output is converted to a digital value by the ADC unit of the Arduino. Here, we fix a threshold value for this output voltage and once the value is reached, the Arduino is programmed to reduce the power supply to the LEDS. This will automatically decrease the LED intensity, thereby eliminating the blind spots due to glare effects. The path will be clearly visible to the driver, increasing the safety.

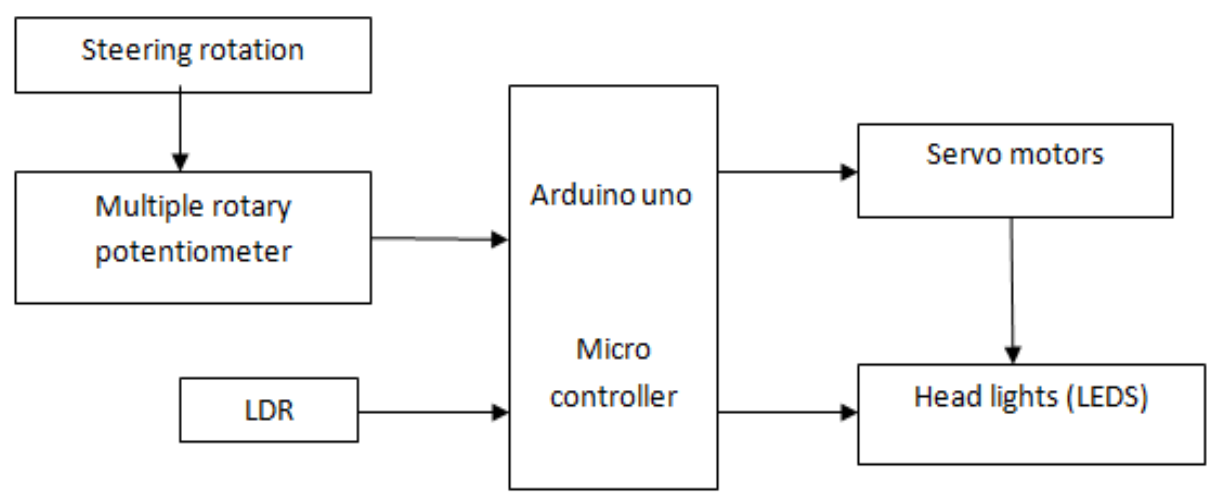

Figure 6: Block Diagram for the Smart Lighting System.

In the system, the potentiometer serves as the steering sensor. When the steering is rotated or tilted, there will be a change in output voltage of the rotary potentiometer. Based on the change in output voltage, the angle through which the steering rotated is determined. This is done by virtual wire library function of the programme code. The voltage is 
converted to numerical angle. This angle divided by twelve, will determine the angle through which the servo motor should be rotated. Based on angle calculated, the micro-controller will generate the pulse width modulation to turn the servo motor in analogy with the steering wheel. The LEDS are attached to the servo motor axis. Thus, the angle of rotation of both the vehicle wheel and the led will be same. Hence the vehicle, when travelling around the road curve, the road will get illuminated well in the direction through which the vehicle is moving. All the objects that are at immediate adjacent to the vehicle can be clearly seen by the driver, improving the path vision.

The multiple turn potentiometer has a maximum resistance of $10 \mathrm{kohms}$ [10]. It is a 3 turn potentiometer, i.e. it can be rotated through an angle of $3 * 360=1080^{\circ}$. In order to determine the angle and pulse width modulation for the servo, the potentiometer is rotated to $540^{\circ}$ and is taken as the reference or default angle. The resistance at this angle will be $5 \mathrm{kohms}$, with $5 \%$ tolerance. The change in resistance from this value (5kohms) is considered to determine whether to rotate the servo in clock or anti clock-wise directions. From the reference position of 5kohms, when the pot is rotated in clock-wise direction, resistance increases gradually and reaches $10 \mathrm{kohms}$ at full rotation, i.e. $1080^{\circ}$. Similarly when the pot is rotated in anti clock-wise direction, the resistance decreases and becomes zero at $0^{\circ}$.

To determine the angle of rotation for servo motor in clock-wise direction, the following table is taken as base for coding the arduino:

Taking the $540^{\circ}$ to be reference or default angle of steering wheel sensor i.e. potentiometer, it is rotated in clockwise direction from $540^{\circ}-1080^{\circ}$. The resistance increased from 5-10kohms as shown at regular intervals. The changed resistance is used by the micro-controller in calculating the pwm for servo motor rotation in clock-wise direction.

\begin{tabular}{|r|r|r|r|}
\hline Potentiometer angle (in degrees) & Change in resistance (in kohms) & corresponding servo motor angle (in degrees) & 0 \\
\hline 540 & 5.83 & 7.5 \\
\hline 630 & 6.66 & 15 \\
\hline 720 & 7.5 & 22.5 \\
\hline 810 & 8.33 & 30 \\
\hline 900 & 9.16 & 37.5 \\
\hline 990 & 10 & 45 \\
\hline
\end{tabular}

Figure 7: Relation between Angular Displacement and resistance Change for Clock-Wise Direction.

From the above table it is very clear that, for every $90^{\circ}$ rotation of potentiometer, the servo motor is rotated through $7.5^{\circ}$. That means the ratio between the angles of pot and servo are in the ratio of 12:1, following the gear ratio as explained earlier.

Similarly, the potentiometer is rotated in counter clock-wise direction from the reference value, i.e. from $540^{0}-0^{0}$. The resistance is changed from $5 \mathrm{kohms}$ to $0 \mathrm{khms}$. The resistance change values are used in programming the microcontroller, to determine the servo motor rotation angle in anti clock-wise direction.

\begin{tabular}{|r|r|r|r|}
\hline Potentiometer angle (in degrees) & Change in resistance (in kohms) & corresponding servo motor angle (in degrees) \\
\hline 540 & 5 & 0 \\
\hline 450 & 4.16 & 7.5 \\
\hline 360 & 3.33 & 15 \\
\hline 270 & 2.5 & 22.5 \\
\hline 180 & 1.66 & 30 \\
\hline 90 & 0.83 & 37.5 \\
\hline 0 & 0 & 45 \\
\hline
\end{tabular}

Figure 8: Relation between Angular Displacement and Resistance Change for Anti Clock-Wise Direction. 
The ratio between potentiometer and servo angles is 12:1 in anti clock-wise direction too, following the gear ratio.

\section{RESULTS}

The following figure shows the set up of the developed system.

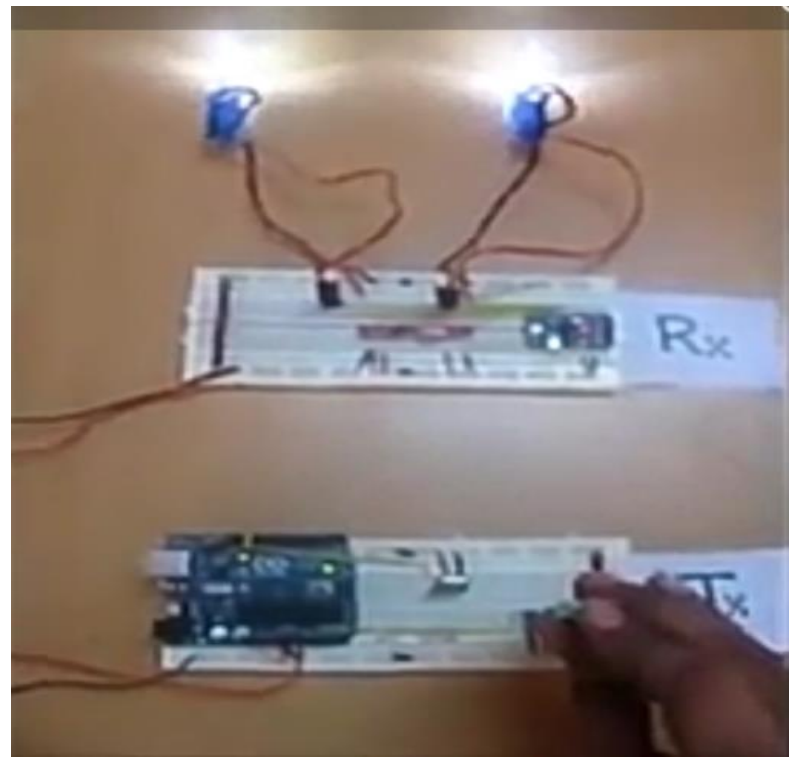

Figure 9: Experimental Setup for the System.

The Arduino UNO is programmed with $\mathrm{C}++$ coding language, utilising the data present in the above tables. The multiple rotary potentiometer is rotated by means of rotary contact manually. Based on the angle through which the pot is rotated, the controller calibrated the servo motor angle with accurate pulse width modulation and the led's attached on servos are rotated through described angle, as shown in tables last column.

The various angles through which the servo motors are rotated are shown in the following figures (both in clock and counter clock-wise):

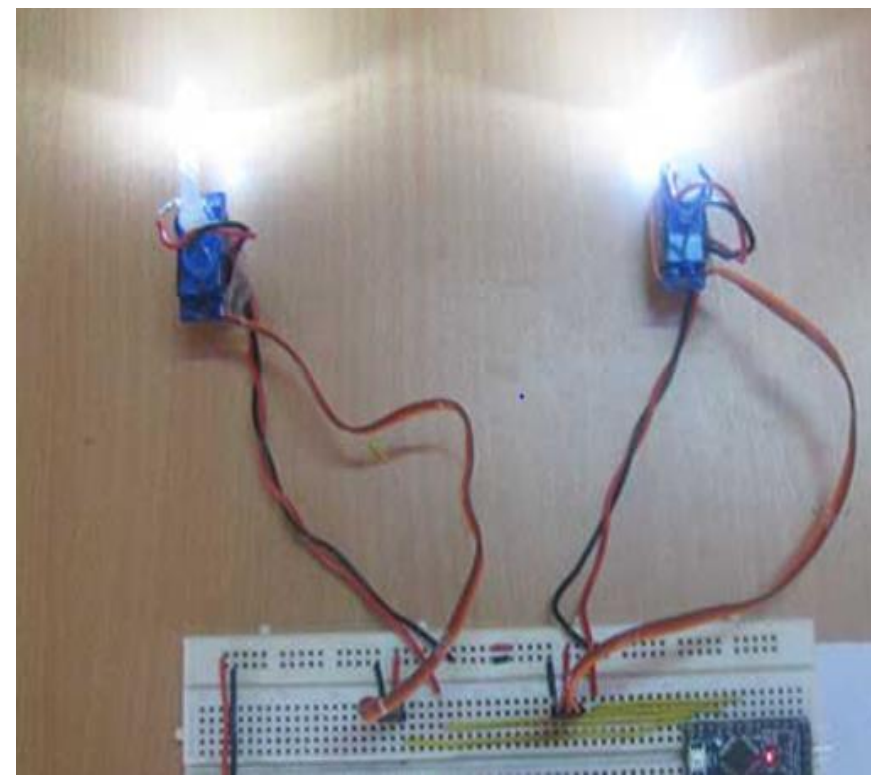

Figure 10: Servo Motor 00 Rotation. 


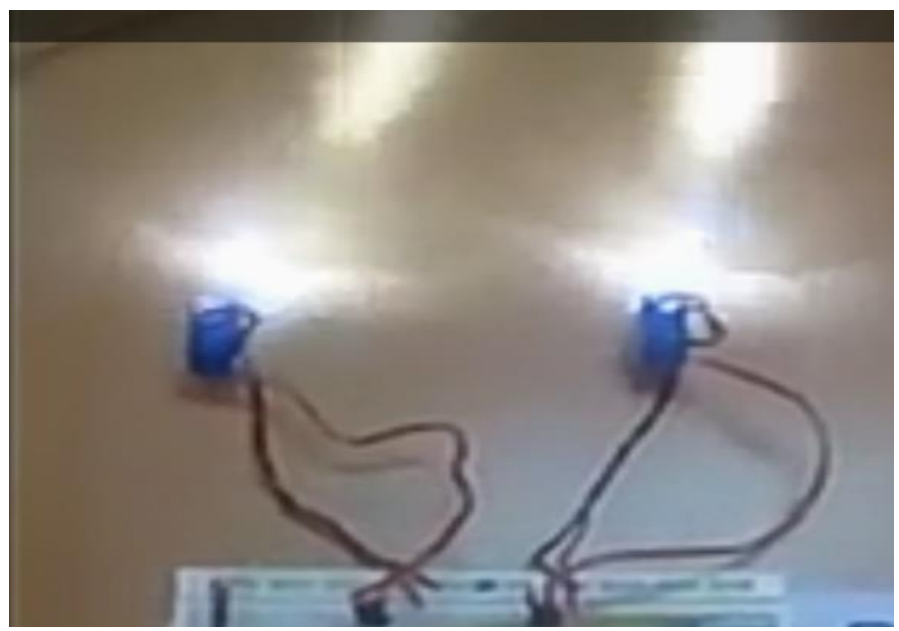

Figure 11: Servo Motor Rotated to 22.50.

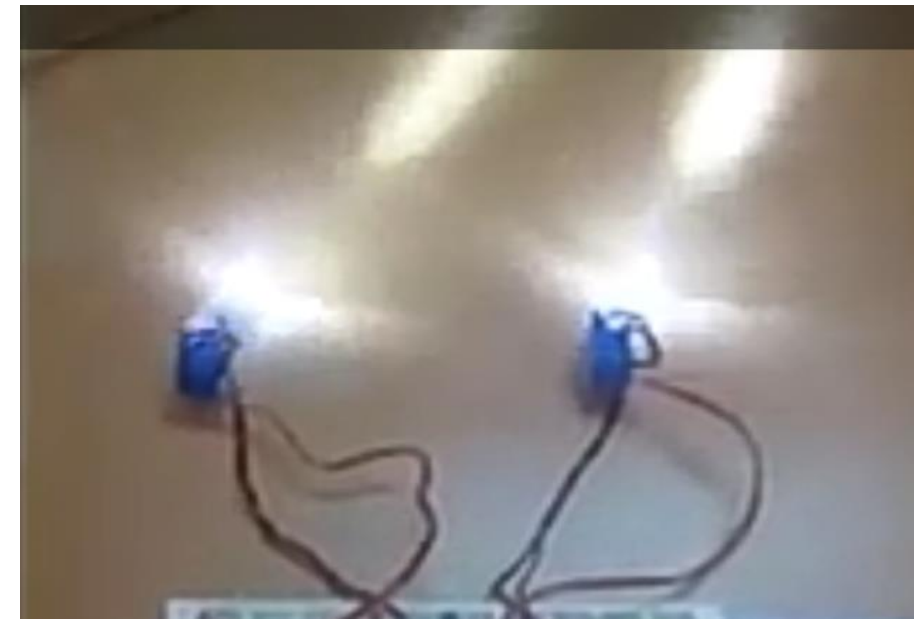

Figure 12: Servo Motor Rotated to 300.

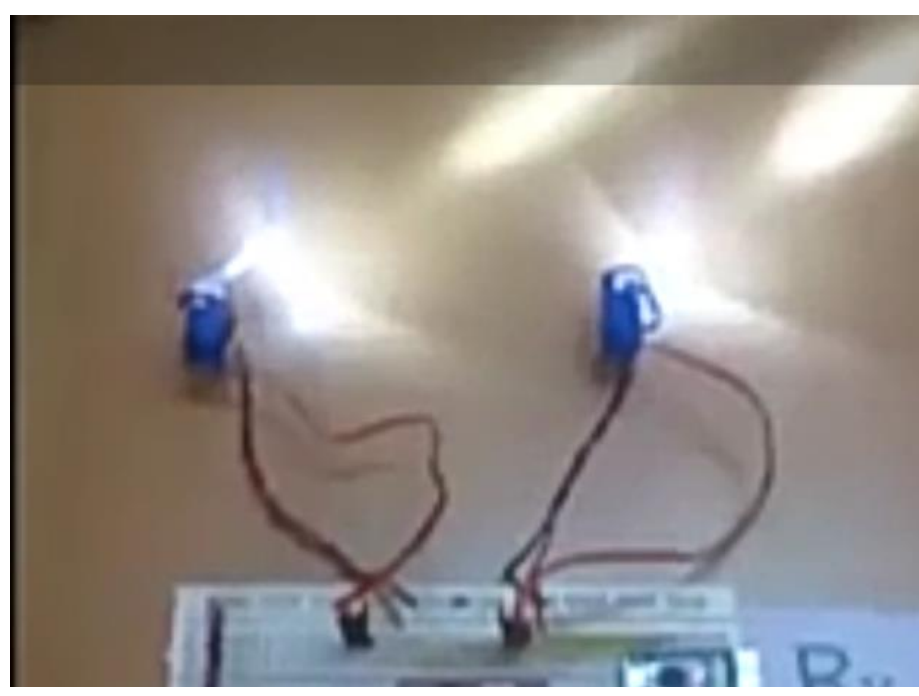

Figure 13: Servo Motor Rotated to Maximum Angle 450.

The above images shows the motor angles rotated in clock-wise direction.

The following are the images when motor is rotated in counter clock-wise direction: 


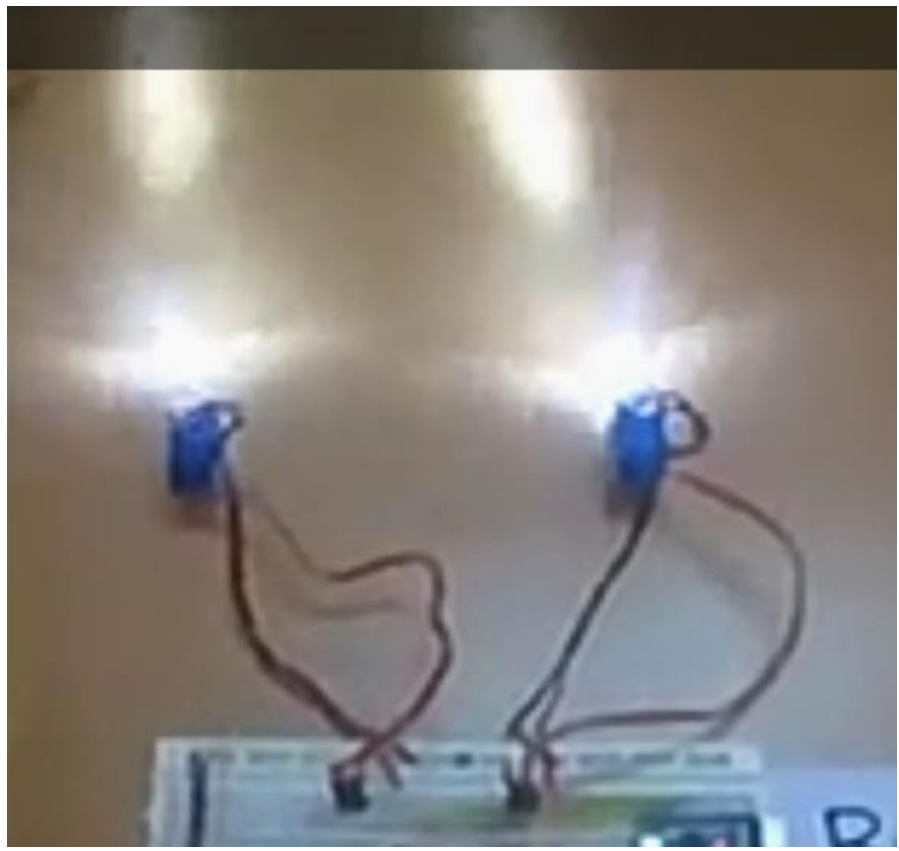

Figure 14: Servo Motor Rotated to 150.

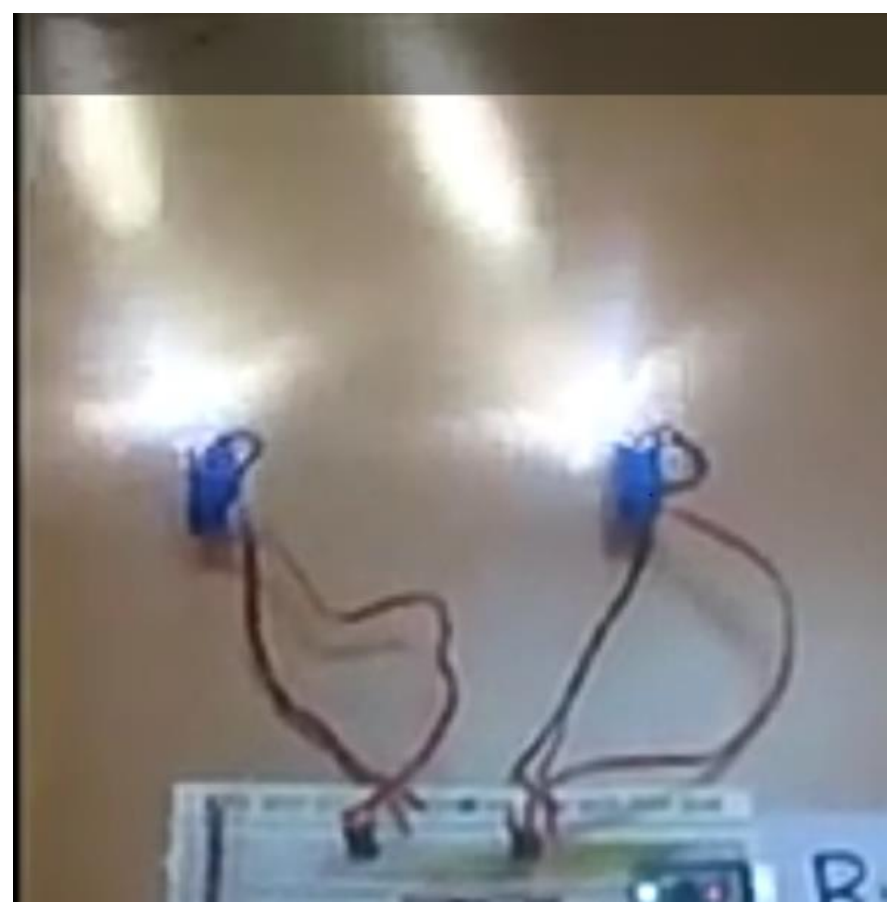

Figure 15: Servo Motor Rotated to 300. 


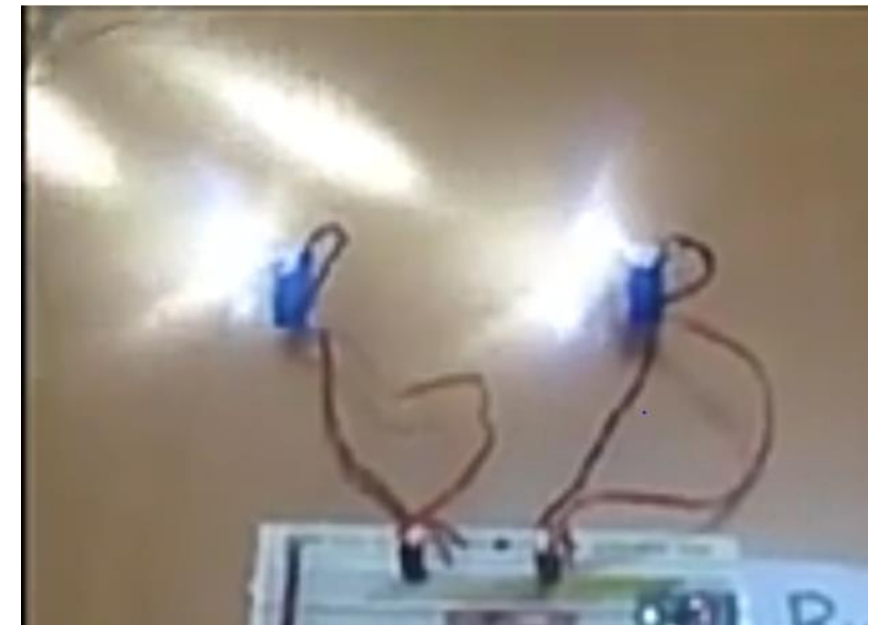

Figure 16: Servo Motor Rotated to 450.

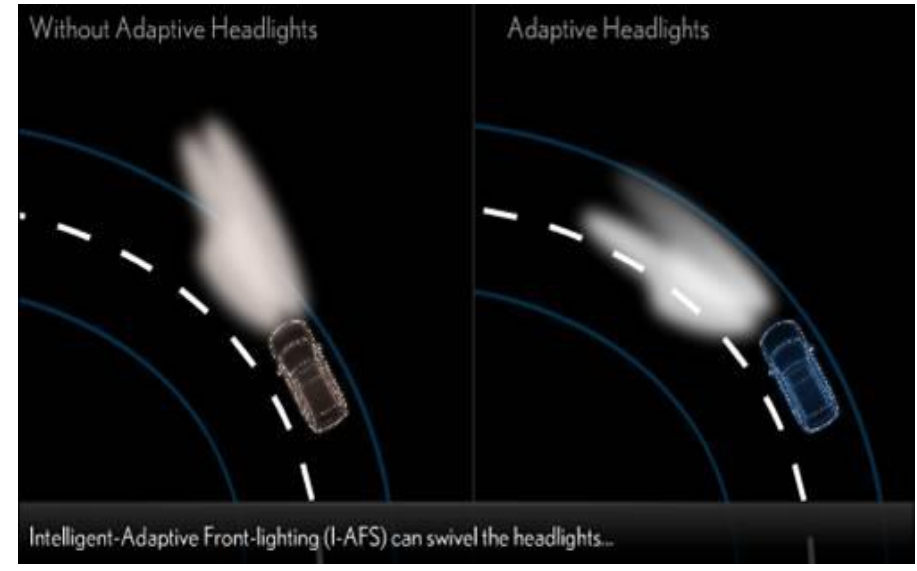

Figure 17: Working of Smart Lighting System.

The LDR sensor interfaced in the system is used to decrease the led intensity to avoid glare effects. For this, the mobile flash light having a power of 10 watts is made to incident on the sensor which would convert the intensity into output voltage. The threshold voltage fixed is $3.5 \mathrm{v}$.

The following figure [17] shows the led glowing with full intensity, since the light incident is too far away from the sensor. The current flowing through it will be very low. Since the threshold value is not met, the led continues to glow at full intensity.

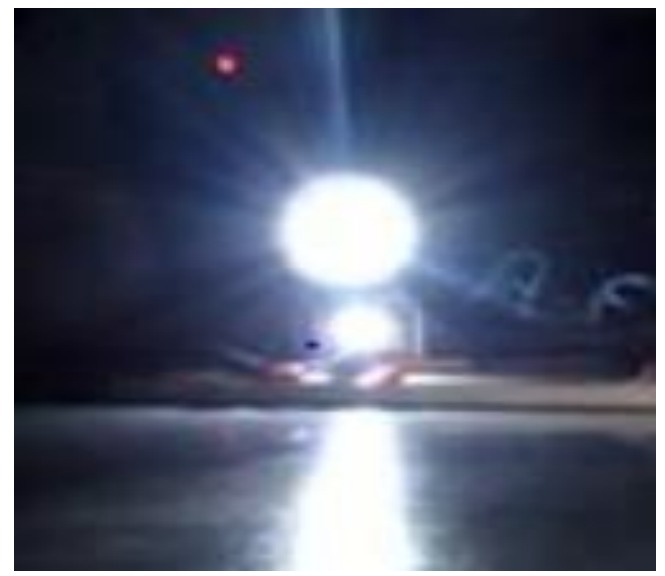

Figure 18: LED Glowing at Full Intensity. 


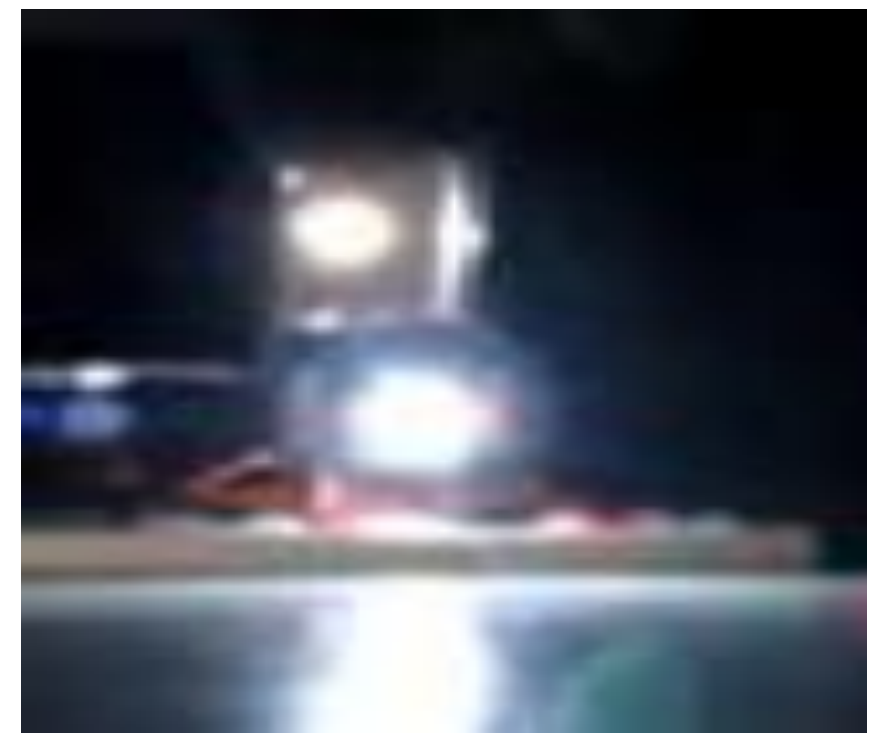

Figure 19: LED Glowing at Reduced Intensity.

When the mobile flash is brought nearer to the sensor gradually, the voltage reached the threshold value of $3.5 \mathrm{v}$ and automatically the LED intensity is reduced by the micro-controller, as shown in figure 18.

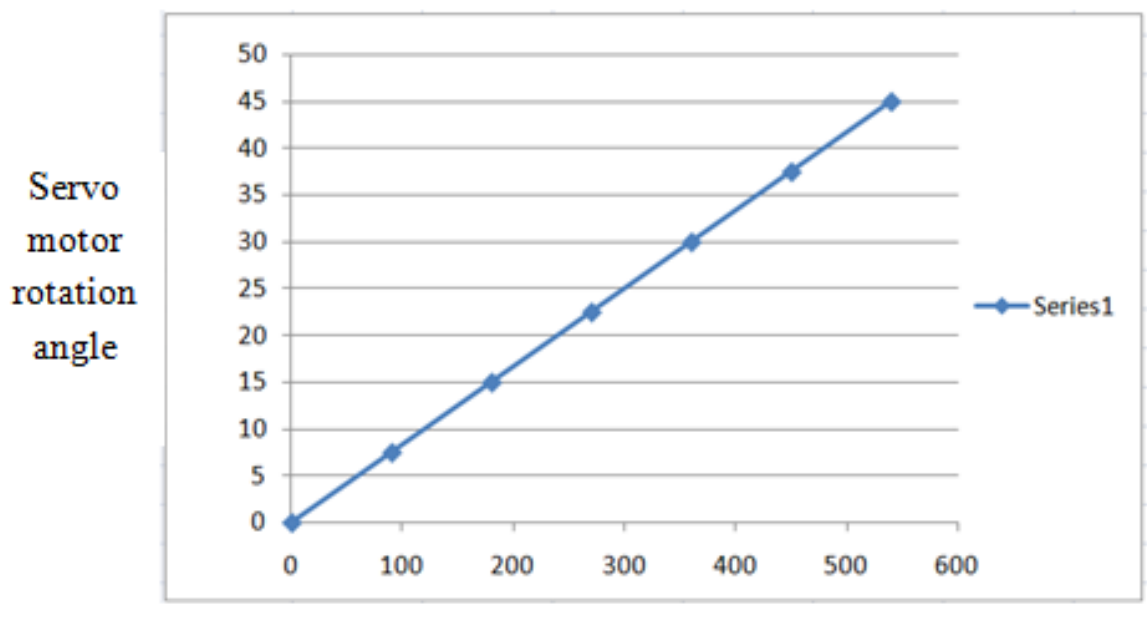

Angle of rotation of potentiometer

Figure 20: A Line Graph Showing the Relation between Potentiometer and Servo Motor Rotation Angles.

\section{CONCLUSION AND FUTURE SCOPE}

A cost effective and highly optimised system has been developed. This system can serve as a best modern solution to avoid blind spots due to glare effects and curvy roads. The LDR sensor is effectively utilised in reducing the head light intensity. With the multiple rotary potentiometer, the servo motor is made to rotate through $45^{\circ}$ in both clock and anti clock-wise direction. This will make the light rays travel along the road curves, illuminating the path well. This system can be adopted to vehicles having any gear ratio. Since the maximum angle rotated is $45^{\circ}$, it can efficiently serve the purpose in all type of vehicles.

In coming future, automatic switching on the indicator light can be developed using the navigation system of the vehicle. The navigation system will generate a pop-up message, when the vehicle is approaching a turn. This pop-up 
message should be sent to the controller and the micro-controller has to be programmed to switch on the indicator light as soon as the message is received. The indicator lights are switched on depending on the type of turn i.e. right or left.

\section{REFERENCES}

1. Shreyas S, Keerthana R, Padmavathi AP- "Adaptive Head Light System for accident prevention". Submitted to International Conference On Recent Trends in Information Technology (2014).

2. Hussein, OMAR ASAAD, and PV RAMANA Rao. "Fault Location and Isolation Using Multi Agent Systems in 16 Buses Distribution System." International Journal of Electrical and Electronics Engineering Research 6 (2016): 21-38.

3. Priyanka Dubal, Alam Sheik- "Adapive Head Lighting System for Vehicles". Submitted to International Journal Of Engineering Research In Computer Science and Engineering (2018).

4. Ravi kumar, Suresh kumar- "Advanced Head Light Controlling System for Automobile". Published in International Research Journal of Engineering and Technology (October 2016).

5. CHUDASAMA, DINESH. "Wearable electronics." International Journal of Electrical and Electronics Engineering Research (IJEEER) 4.5 (2014): 27-32.

6. Klayani G, Ramesh M- “A Survey On LIN/CAN Based Automatic Lighting System”. Published in International Journal of Innovative Research in Science,Engineering and Technology (May 2017).

7. Vaishali D, Bachute M R- "Survey on Adaptive Front Lighting System". Published in International Journal of Advanced Research (2016).

8. Chowdary, Undavalli Vivek, et al. "Home automation system using IR sensors." International Journal of Electrical and Electronics Engineering 4.6 (2015): 11-1.

9. Shinde Ganesh R, Jadhav Tushar D- “Adaptive Head Light System”. Publication of International Journal of Informative \& Futuristic Research (March 2015)

10. Nath, Vikas, Nitin Nayak, and Ankit Goel. "Green banking practices-A review." IMPACT: International Journal of Research in Business Management (IMPACT: IJRBM) Vol 2 (2014): 45-62.

11. Prithvi Raj CH, Archana B- "Smart Adaptive Vehicle Lighting System". Published in International Journal of Current Engineering And Scientific Research (IJCESR)-2017.

12. Night Driving-Night time car accidents statistics-Pines Saloman Injury Lawyers.

13. Car Bibles Blog- How Car Steering System Works.

14. Precision Pots Multi-turn. Bourns Official Website.

15. Troxler effects. A article published in Telangana Today (July 2018). 


\section{AUTHORS PROFILE}

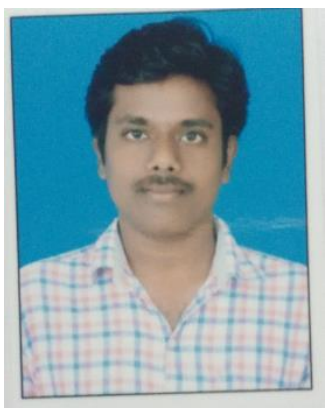

[1] Mr. SANTHOSH KUMAR ANNA is currently pursuing Masters Of Technology in Mechanical Engineering with specialization in Robotics \& Mechatronics at Koneru Lakshmaiah Educational Foundation. He obtained his Bachelors degree in engineering from KAKATIYA UNIVERSITY, WARANGAL. During his academic research in B.Tech, he worked on Observation of physical characteristics of HIGH ENTROPY ALLOYS. Currently he is working on development of optimized and cost effective system for SMART LIGHTING SYSTEM FOR VEHICLES TO AVOID BLIND SPOTS.

EMAIL: annasanthoshkumar@gmail.com ; MOBILE \& WHATSAPP NO: 9989412922

LINKEDIN: NOT AVAILABLE

FB PROFILE: NOT AVAILABLE

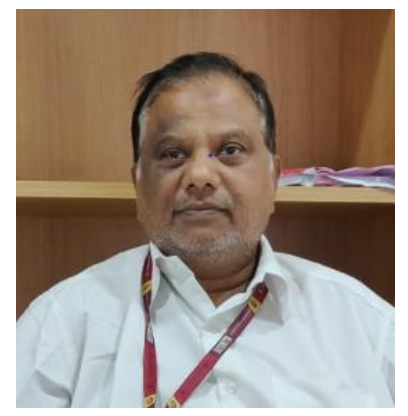

[2] Mr. SHUJAYAT KHAN is currently working as a project manager at Koneru Lakshmaiah Educational Foundation. He finished his BE in Mechanical from Andhra University, ME in Mechanical from JNTU Hyderabad and Master of Financial Management from Pondicherry University. He worked in Hindustan Aeronautics Limited for 19 years as a executive engineer. Later, he worked as General Manager and CEO of Central Institute of Tool Design, Hyderabad for 11 years. During this period, he guided many students and aspirants in their academic projects and research works.

EMAIL: shujayatkhan@kluniversity.in MOBILE \& WHATSAPP NO: 9959148618

LINKEDIN: NOT AVAILABLE FB PROFILE: NOT AVAILABLE 

